Madrygal. Revista de Estudios Gallegos

ISSN: 1138-9664

\title{
La temprana inmigración gallega en Buenos Aires: condicionantes y caracte- rísticas de su inserción socio-ocupacional
}

\author{
Nadia Andrea de Cristóforis ${ }^{1}$
}

Recibido: 4 de febreiro de 2016 / Aceptado: 14 de setembro de 2016

Resumen. A fines de la etapa colonial las emigraciones de los gallegos hacia Buenos Aires se incrementaron. Este fenómeno estuvo estimulado por el aumento de la tasa emigratoria en el noroeste hispánico y por el atractivo ejercido por la capital virreinal. En este trabajo nos concentraremos en los procesos de inserción socio-ocupacional de los gallegos en el Buenos Aires tardo-colonial. Para ello, nos basaremos principalmente en documentación nominativa (los padrones de habitantes de 1806-1807 y 1810 o las actas matrimoniales) que será complementada con otra de índole más cualitativa (testamentos de gallegos o expedientes varios del Archivo General de la Nación de la Argentina). En primer lugar, analizaremos las características de la estructura ocupacional de los gallegos. En segundo lugar, focalizaremos las actividades comerciales desplegadas por dichos inmigrantes, explicando en qué consistieron y cuáles fueron las vías de ingreso al ejercicio mercantil. Consideramos que los rasgos del comercio rioplatense, que ofrecía accesibles vías de ingreso a los recién llegados, y la asistencia brindada por redes étnicas y familiares, permitieron que los gallegos pudieran insertarse en los circuitos de intercambios y permanecer en ellos con variable éxito. Asimismo, el importante grado de inserción en el ámbito mercantil pudo haber incidido sobre los nichos ocupacionales que quedaron configurados en el período de la inmigración masiva de gallegos.

Palabras clave: Inmigrantes; gallegos; ciudad de Buenos Aires; inserción socio-ocupacional.

\section{[gl] A temperá inmigración galega en Bos Aires: condicionantes e características da súa inserción socio-ocupacional}

Resumo. A fins da etapa colonial as emigracións dos galegos cara a Bos Aires incrementáronse. Este fenómeno estivo estimulado polo aumento da taxa emigratoria no noroeste hispánico e polo atractivo exercido pola capital do vicerreinado. Neste traballo concentrarémonos nos procesos de inserción socio-ocupacional dos galegos no Bos Aires tardocolonial. Para iso, basearémonos principalmente en documentación nominativa (os padróns de habitantes de 1806-1807 e 1810 ou as actas matrimoniais) que será complementada con outra de índole máis cualitativa (testamentos de galegos ou expedientes varios do Archivo General de la Nación da Arxentina). En primeiro lugar, analizaremos as características da estrutura ocupacional dos galegos. En segundo lugar, focalizaremos as actividades comerciais despregadas polos devanditos inmigrantes, explicando en que consistiron e cales foron as vías de ingreso ao exercicio mercantil. Consideramos que os trazos do comercio rioplatense, que ofrecía accesibles vías de ingreso aos recentemente chegados, e a asistencia brindada por redes étnicas e familiares, permitiron que os galegos puidesen inserirse nos circuítos de intercambios e permanecer neles con variable éxito. Así mesmo, o importante grao de inserción no ámbito mercantil puido incidir sobre os nichos ocupacionais que quedaron configurados no período da inmigración masiva de galegos.

Palabras chave: Inmigrantes; galegos; cidade de Bos Aires; inserción socio-ocupacional.

\section{[en] The Early Galician Immigration in Buenos Aires: Conditions and Character- istics of its Socio-occupational Insertion}

\begin{abstract}
The migrations of Galicians to Buenos Aires increased at the end of the colonial period. This phenomenon was stimulated by the increase in the emigration rate in the Spanish Northwest and the attraction exerted by the colonial capital. In this paper we will focus on the processes of socio-occupational insertion of the Galicians in the late colonial Buenos Aires. To do so, we will base mainly on nominative documentation (the registers of inhabitants of 1806-1807
\end{abstract}

1 Universidad de Buenos Aires, Instituto de Investigaciones “Gino Germani”, Consejo Nacional de Investigaciones Científicas y Técnicas. E-mail: ndecristoforis@sociales.uba.ar 
and 1810 or the matrimonial proceedings) which will be complemented by qualitative sources (wills of Galician immigrants or several records of the Archivo General de la Nación of Argentina). First, we will analyze the characteristics of the Galicians' occupational structure. Secondly, we will focus on business activities undertaken by these immigrants. We will explain in what they consisted and what were the ways of entry to the commercial exercise. We believe that the traits of Río de la Plata trade, offering accessible ways of entry to newcomers, and the assistance provided by ethnic and family networks, allowed Galicians to insert in circuits of exchanges and remain in them with variable success. Also, the significant degree of insertion in the commercial field could have impacted on occupational niches that were configured in the period of Galicians' mass immigration.

Keywords: Immigrants; Galicians; City of Buenos Aires; Socio-occupational Insertion.

Sumario. 1. Introducción. 2. La inmigración de los gallegos en el Buenos Aires tardo-colonial. 3. La inserción socio-laboral del colectivo inmigratorio. 4. El peso de las actividades comerciales. 5. Las formas de ingreso al ejercicio comercial. 6. Conclusiones. 7. Referencias Bibliográficas.

Como citar: De Cristóforis, N. A. (2017): "La temprana inmigración gallega en Buenos Aires: condicionantes y características de su inserción socio-ocupacional", $M a$ drygal. Revista de Estudios Gallegos 20 (Núm. especial), pp. 59-72.

\section{Introducción}

En las últimas décadas del siglo XVIII Galicia experimentó un aumento de su tasa emigratoria, que se motivó en factores de tipo demográfico o socio-económico (Eiras Roel 1991: 27 34, Eiras Roel y Rey Castelao 1992: 155-159). Además de los tradicionales desplazamientos dentro de la península (hacia Castilla, Andalucía o Portugal, principalmente), se intensificaron las emigraciones hacia el Continente Americano, que se dirigieron preponderantemente hacia el espacio antillano o rioplatense
(Villares y Fernández 1996: 65-69). Dentro de este último, Buenos Aires o Montevideo se convirtieron en importantes ámbitos de atracción de la población que partía de Galicia y otras regiones españolas. En ambas ciudades los gallegos se constituyeron en el principal grupo peninsular, desde un punto de vista regional ${ }^{2}$.

Con interesantes aportes, los estudios sobre la inmigración desde el noroeste hispánico hacia la Argentina se concentraron preponderantemente en el período masivo, aquel que presenció la llegada de un vasto contingente de gallegos al país austral entre 1880 y 1930 , aproximadamente ${ }^{3}$. En general, los flujos tempranos, es decir, los producidos entre la etapa colonial y el inicio de la independiente, quedaron soslayados en la historiografía argentina sobre la inmigración. Algunos factores influyeron en esta tendencia: desde cuestiones metodológicas (la ausencia de fuentes estadísticas para dicho período), conceptuales (las dificultades de concebir como "emigrantes" a los súbditos de la Corona española que se desplazaron dentro del espacio imperial) o incluso historiográficas (la incidencia de una corriente como la de Annales, que tendió a interpretar a las sociedades de Antiguo Régimen como "inmóviles" o estables) (Akerman, Johansen y Ostergren 1990: 4, Devoto 1992: 50-55). En este sentido, nuestro trabajo apuntará a subsanar ciertas "lagunas" en el conocimiento de los comienzos de la inmigración gallega en el Río de la Plata, corrientes que constituyeron la base sobre la cual se articularon los movimientos inmigratorios de la etapa masiva, si tenemos en cuenta que estos últimos se conformaron a partir de las redes microsociales iniciadas por los "pioneros" arribados precedentemente.

2 Para el caso de Montevideo, cf. Bentancur 1999: 103, Zubillaga Barrera 1999: 175-190. En relación con Buenos Aires hemos logrado analizar de manera complementaria los padrones de habitantes de 1806-1807 y 1810 , con el fin de relevar el número de gallegos instalados en la mencionada ciudad, a fines de la etapa colonial. A partir del examen de los 16 barrios o cuarteles disponibles (de los 20 en que se dividía la ciudad en ese entonces) localizamos 795 gallegos (779 varones y 16 mujeres). Sin embargo, esta cifra es mínima y provisoria pues no toma en consideración a los inmigrantes que estaban ubicados en los cuatro barrios cuyas planillas han desaparecido y a los que declararon ser oriundos de España, omitiendo su procedencia regional o local. Cf. Archivo General de la Nación (Buenos Aires, Argentina; en adelante: AGN), División Colonial (en adelante: DC), Sección Gobierno, Sala IX (en adelante: S IX) 9-7-7, Padrones generales de los habitantes de Buenos Aires de 1806 y 1807; S IX 10-7-1, Censo de Buenos Aires de 1810.

3 Sin proponernos ser exhaustivos, podríamos mencionar algunos trabajos significativos vinculados al período mencionado: Da Orden 2001, Farias Iglesias 2010, Marquiegui 1993, Moya 2001 y Núñez Seixas 2000, 2002. 
Además, nos concentraremos en un aspecto particular de los procesos de integración de los gallegos en el Buenos Aires tardo-colonial: su inserción socio-laboral, haciendo hincapié en sus características y factores condicionantes. Creemos que el tipo de estructura ocupacional que presentó la comunidad del noroeste hispánico en la capital virreinal condicionó de manera importante el tipo de actividades económicas en las que se ubicaron los inmigrantes gallegos entre mediados del siglo XIX y comienzos del XX. Si bien en esta última etapa el peso de las ocupaciones dependientes y/o poco calificadas (por ejemplo, en el sector de los servicios urbanos) fue aumentando progresivamente hasta alcanzar un lugar preponderante, el comercio, sobre todo el minorista desarrollado en ámbitos urbanos, siempre constituyó un importante "nicho laboral" para los oriundos de Galicia, tanto en el período de historia independiente (Cagiao Vila y Núñez Seixas 2007: 33-40, De Cristóforis 2010: 200201; Núñez Seixas 2007: 30-31, 2014: 316317) como en el tardo-colonial. Para apoyar con evidencia documental esta última idea nos basaremos principalmente en fuentes nominativas (los padrones de habitantes de Buenos Aires de 1806-1807 y 1810 o las actas matrimoniales) que serán complementadas con otras de índole más cualitativa (testamentos de gallegos o expedientes varios del Archivo General de la Nación de la Argentina).

\section{La inmigración de los gallegos en el Bue- nos Aires tardo-colonial}

Los desplazamientos desde Galicia hacia Buenos Aires se motivaron en diversos factores: los que actuaron en el noroeste hispánico, ya mencionados, se conjugaron con otros que operaron en el espacio Atlántico o en el ámbito de destino, como la introducción de los Correos Marítimos y la expansión demográfica y económica de la capital virreinal, en los años finales de la etapa colonial.
En efecto, la instauración de los Correos Marítimos en A Coruña (1764) y la inauguración de una línea regular de paquebotes que conectó la mencionada ciudad con Montevideo (1767), favoreció el transporte ultramarino de la correspondencia, las mercancías y las personas (Cagiao Vila y Pazos Pazos 2007: 22-27, Garay Unibaso 1987, Lelo Bellotto 1971). La información sobre las oportunidades de inserción y movilidad social en el espacio austral se difundió con mayor rapidez por las áreas litorales o prelitorales del noroeste peninsular, principalmente por la acción de los capitanes, marineros y retornados. De allí que los emigrantes que se dirigieron a Buenos Aires fueran oriundos de ámbitos costeros o semi-costeros, por lo general de localidades que presentaban un importante desarrollo urbano dentro de la región (A Coruña, Ferrol, Vigo o Santiago de Compostela) ${ }^{4}$. A Coruña, ciudad que aportó el mayor número de emigrantes a la sociedad porteña entre 1770 y 1812, gozaba de una situación privilegiada como espacio de contacto entre el noroeste hispánico y el Río de la Plata, dado que no sólo era el punto de partida de los embarcaciones de los Correos Marítimos, sino que también había quedado habilitada para el comercio directo con Indias a partir de 1778 .

Desde el lado sudamericano, las transformaciones experimentadas por Buenos Aires también impulsaron los procesos inmigratorios hacia la misma. Las reformas borbónicas de la década del setenta (libre internación a Chile y Perú, comercio libre con los más importantes puertos peninsulares) afianzaron su ascenso comercial y además, su designación como capital del Virreinato del Río de la Plata (1776) la dotó de una nueva centralidad burocrático-administrativa (Figueira 2000: 117-123). Como efecto del crecimiento vegetativo, de la llegada de población esclava, pero especialmente, debido a las migraciones del interior virreinal y ultramarinas, la población de Buenos Aires creció notablemente a fines del siglo XVIII y comienzos del XIX, alcanzando unos 42540

4 Ello se deduce del análisis de las jurisdicciones eclesiásticas y localidades de origen de los peninsulares en consideración, realizado a partir de la siguiente documentación: Archivos Parroquiales de Buenos Aires, Actas Matrimoniales, Iglesia Catedral de Buenos Aires (Libros 5, 6 y 7, 1770-1812); Parroquia de Nuestra Señora de la Concepción del Alto de San Pedro (Libros 1 -Tomo 2-, 2, 3 y 4, 1770-1812); Parroquia de Nuestra Señora del Socorro (Libros 1 y 2, 1783-1812); Parroquia de Nuestra Señora de la Piedad (Libro 1 -Tomos 1 y 3-, 1770-1812); Parroquia de San Nicolás de Bari (Libro sin número 1? y 3, 1770-1775; 1802-1812); Parroquia de Nuestra Señora de Monserrat (Libros 1 y 2, 1770-1812). 
habitantes en 1810, de los cuales más de 4300 eran españoles-europeos, según nuestros propios cálculos (Facultad de Filosofía y Letras 1920b: 332-355 y 356-389, Johnson 1979: 110, Johnson y Socolow 1980: 331).

Los gallegos se desplazaron al Buenos Aires tardo-colonial a través de diversos mecanismos: la designación oficial para desempeñar actividades burocráticas o militares, la incorporación al séquito de algún señor en calidad de "criados", el "llamado" de algún funcionario o pariente ya instalado del otro lado del océano o incluso el pasaje ilegal, fenómeno muy generalizado para la época (Márquez Macías 1989: 16, Pérez 2010: 187-212, Rey Castelao 2001: 43-44) $)^{5}$. Según las investigaciones de Márquez Macías (1989: 46-47) entre 1765 y 1824, 332 gallegos solicitaron licencia oficial para trasladarse a las Indias, de los cuales sólo 26 declararon dirigirse a Buenos Aires. Esta última cifra contrasta con los 795 gallegos que pudimos localizar en dicha ciudad hacia 1810 , lo que nos alerta sobre el hecho de que no todos ellos arribaron legalmente, entre otras razones, por los crecientes obstáculos burocráticos impuestos por el reformismo borbónico para obtener la licencia de embarque (Delgado Ribas 1982: 118; Márquez Macías 1991, 1993: 238, 1995: 67-122).

Dentro de la ciudad de Buenos Aires los inmigrantes gallegos no se distribuyeron de manera uniforme, sino que se cohesionaron en torno a sus barrios o cuarteles céntricos, en una zona de antigua edificación, caracterizada por elevadas densidades de población y por un constante crecimiento demográfico desde mediados del siglo XVIII (García Belsunce 1976: 60, Johnson y Socolow 1980: 341-342). Los oriundos del noroeste hispánico se concentraron principalmente en los barrios $\mathrm{n}^{\circ} 8$ y $\mathrm{n}^{\mathrm{o}} 13$, que eran contiguos y conformaban un área rectangular ${ }^{6}$. Algunos de sus ejes de circulación de este a oeste eran las calles Villota,
Reconquista, Lezica, Sans Valiente y Mansilla y de norte a sur: Ribas, Parejas, La Correa, Lasala, Unquera y Victoria ${ }^{7}$. Se trataba de un espacio algo distante del Río de la Plata, donde se habían extendido las actividades comerciales. Esta localización en el ámbito mercantil de la ciudad no fue casual, sino que fue consecuencia y causa del desempeño de actividades comerciales, por parte de un número importante de gallegos, como pondremos de relieve a continuación.

\section{La inserción socio-laboral del colectivo in- migratorio}

Como ya señalamos, en nuestro análisis de la inserción ocupacional de los gallegos en el Buenos Aires tardo-colonial nos hemos basado, entre otras fuentes, en los padrones de población de 1806-1807 y 1810. En relación con el tratamiento de esta documentación tenemos que tener presente algunas advertencias metodológicas. En primer lugar, un problema de difícil superación: el de las limitaciones inherentes a las clasificaciones de las actividades económicas realizadas por los empadronadores de la colonia y por los investigadores actuales, que introdujeron o imponen criterios más o menos arbitrarios a una realidad social mucho más dinámica y fluida que la imagen que se deriva de los rígidos encasillamientos en categorías preestablecidas ${ }^{8}$. Los estudios sobre la etapa tardo-colonial han empleado diferentes cuadros clasificatorios para describir las actividades económicas de la población rioplatense (por ejemplo, Johnson y Socolow 1980: 342-344, Moreno 1965: 154-155). Nosotros nos aproximaremos a la clasificación propuesta por el equipo dirigido por García Belsunce (1976: 107-133), lo que implica considerar los siguientes tipos de actividades: "comerciales", "militares", "artesanales y/o calificadas", "marítimas", "dependientes y/o poco calificadas",

5 Cf. también AGN, Fondo Biblioteca Nacional (en adelante: FBN), Patagonia. Documentos del Archivo de Indias, Leg. n 196,1778 , f. 8.

6 AGN, DC, Sección Gobierno, S IX 9-7-7, Padrones generales de los habitantes de Buenos Aires de 1806 y 1807 ; S IX 10-7-1, Censo de Buenos Aires de 1810.

7 Los nombres actuales de las calles mencionadas son los siguientes: Villota = Hipólito Yrigoyen, Reconquista $=$ Rivadavia, Lezica $=$ Bartolomé Mitre, Sans Valiente $=$ Juan D. Perón, Mansilla $=$ Sarmiento, Ribas $=$ Carlos Pellegrini, Parejas $=$ Suipacha, La Correa $=$ Esmeralda, Lasala $=$ Maipú, Unquera $=$ Florida, Victoria $=$ San Martín .

8 Para algunos intentos de superación del problema comentado, cf. Botelho y van Leeuwen 2012, Gribaudi y Blum 1990. 
"administrativas", "rurales", "religiosas", "profesionales", y "varias" (ver Cuadro 1) .

Los otros señalamientos metodológicos se vinculan con la naturaleza de los padrones de población que hemos examinado. Por un lado, es importante tener en cuenta que algunos de los comerciantes y artesanos, además de desempeñarse en sus propios oficios, tenían una filiación militar, es decir, estaban alistados en las tropas veteranas de la corona española o en las milicias urbanas conformadas a raíz de las Invasiones Inglesas a Buenos Aires (1806$1807)^{10}$. De los 345 comerciantes gallegos, 37 desplegaron al mismo tiempo actividades militares. Estas últimas también fueron llevadas a cabo por 3 de los artesanos de la misma procedencia. En el Cuadro 1 se contabilizaron solamente las actividades económicas principales de cada sujeto. Es decir, en el caso de un comerciante, que además formaba parte del Tercio de Gallegos, por ejemplo, tomamos en consideración la primera ocupación, dado que la segunda era complementaria de la misma. Por otro lado, los padrones analizados fueron originados con el fin de conocer a la población en edad de servicio y por ello los empadronadores estaban probablemente más preocupados por dejar sentado en sus planillas dónde estaban enrolados los hombres, antes de cuáles eran sus "ejercicios". Esto pudo haber provocado que muchos alcaldes consignaran sólo el alistamiento o cargo militar de los habitantes, y no sus oficios civiles. Por lo tanto, podemos suponer que las actividades militares se hallan en parte sobredimensionadas y por el contrario, las otras, infravaloradas.
Por último, señalaremos que los inmigrantes gallegos empadronados no siempre declararon sus actividades económicas. De los 795 españoles de dicho origen que hemos podido identificar en las planillas disponibles, encontramos la indicación de la ocupación en el caso de 622 varones. Sobre la base de esta última información elaboramos el Cuadro 1.

\begin{tabular}{|l|l|l|}
\multirow{2}{*}{ Tipos de actividades } & \multicolumn{2}{|c|}{ Inmigrantes gallegos } \\
\cline { 2 - 3 } & Números & Porcentajes \\
\hline Comerciales & $345^{*}$ & $55,5 \%$ \\
\hline Militares & 160 & $25,7 \%$ \\
\hline Artesanales y/o calificadas & $57^{* *}$ & $9,2 \%$ \\
\hline Marítimas & 22 & $3,5 \%$ \\
\hline $\begin{array}{l}\text { Dependientes y/o poco } \\
\text { calificadas }\end{array}$ & 10 & $1,6 \%$ \\
\hline Administrativas & 7 & $1,1 \%$ \\
\hline Rurales & 6 & $1 \%$ \\
\hline Religiosas & 5 & $0,8 \%$ \\
\hline Profesionales & 2 & $0,3 \%$ \\
\hline Varias & 8 & $1,3 \%$ \\
\hline Total & $\mathbf{6 2 2}$ & $\mathbf{1 0 0} \%$ \\
\hline
\end{tabular}

Cuadro 1. Ocupaciones de los inmigrantes gallegos en la ciudad de Buenos Aires, hacia $1810^{11}$

A partir del Cuadro 1 podemos constatar la preeminencia alcanzada por las ocupaciones comerciales, que eran desarrolladas por más de la mitad del conjunto de gallegos por nosotros considerado. En orden decreciente de importancia se ubicaban las actividades militares, artesanales y/o calificadas, marítimas, dependientes $\mathrm{y} / \mathrm{o}$ poco calificadas, administrativas,

9 En cada una de las mencionadas categorías incluimos varios oficios consignados en los padrones de población (por orden alfabético, dentro de cada categoría): Comerciales: almacenero, comerciante, dependiente o mozo, pulpero, tendero. Militares: alférez, artillero, cabo, capitán, comandante, oficial, sargento, soldado, subteniente, tambor, teniente. Artesanales y/o calificadas: albañil, armero, balanceador, boticario, capataz, carpintero, carretillero, confitero, cordelero, empleado, fabricante de velas, herrero, músico, ojalatero, panadero, platero, relojero, sastre, silletero, sombrerero, talabartero, tonelero, zapatero. Marítimas: barquero, calafate, dueño de barco, lanchero, marinero, patrón de barco, piloto. Dependientes y/o poco calificadas: cantero, celador, farolero, guarda, jornalero, lustrador, peluquero, peón, repartidor de pan. Administrativas: empleados y funcionarios de las siguientes instituciones: Aduana, Correos, Real Audiencia, Tribunal de Cuentas. Rurales: estanciero, hacendado, hortelano, labrador, quintero. Religiosas: clérigo, fraile, presbítero, prior. Profesionales: médico. Varias: estudiante, militar retirado.

10 En la terminología de la época, se denominaba "tropa veterana" a las unidades militares regulares al servicio de la corona española.

11 *Cifra que incluye a 37 gallegos que, además de sus actividades comerciales, desempeñaban otras de tipo militar. **Cifra que involucra a 3 gallegos que, además de sus tareas artesanales, desplegaban otras de índole militar. Fuentes: Archivo General de la Nación (Buenos Aires, Argentina), División Colonial, Sección Gobierno, Sala IX 9-7-7, Padrones generales de los habitantes de Buenos Aires de 1806 y 1807; Sala IX 10-7-1, Censo de Buenos Aires de 1810. 
rurales, religiosas y profesionales. Los últimos cuatro tipos de tareas eran llevadas a cabo por una proporción muy minoritaria de gallegos, quienes eran proclives a ubicarse en el comercio y el servicio militar. En relación con este último, debemos tener presente dos importantes estímulos para la ampliación de los efectivos del ejército en Buenos Aires: por un lado, como ya sugerimos, las Invasiones Inglesas, que promovieron el enrolamiento en las milicias de unos siete mil hombres (los gallegos quedaron integrados mayoritariamente en el Tercio de Gallegos), de los cuales alrededor de tres mil estaban aún alistados antes de la Revolución de Mayo de 1810 (Halperín Donghi 1968: 84). Por otro lado, la existencia de banderas de reclutas en la península, encargadas de "enganchar" hombres para el servicio en las Indias (en 1784 se creó la bandera en A Coruña, que reclutó soldados para servir en los cuerpos veteranos con asiento en el Río de la Plata) (Pérez 2010: 190). En lo que resta de este trabajo nos detendremos en el caso de las ocupaciones comerciales, por tratarse de un aspecto poco indagado de la inmigración gallega en la ciudad porteña y además, por su importancia cuantitativa y cualitativa dentro de la comunidad del noroeste hispánico allí asentada.

\section{El peso de las actividades comerciales}

Dentro de la ciudad de Buenos Aires, mientras que el $55,5 \%$ de los gallegos se insertaron en actividades mercantiles, un $28,7 \%$ de la población activa libre y un $51,8 \%$ de la española en general siguieron esa misma tendencia (García Belsunce 1976: 107-133, 264). Como vemos, la inclinación por el comercio fue muy fuerte entre los oriundos del noroeste hispánico, mayor que en el caso de la población activa libre e incluso, que en el de la peninsular considerada globalmente.

Dentro del ámbito mercantil, los inmigrantes gallegos se desempeñaron como pulperos, comerciantes, dependientes, tenderos y almaceneros, en orden decreciente de importancia (Ver el Cuadro 2).

\begin{tabular}{|l|l|l|}
\multirow{2}{*}{$\begin{array}{l}\text { Tipos de actividades } \\
\text { comerciales }\end{array}$} & \multicolumn{2}{|c|}{ Inmigrantes gallegos } \\
\cline { 2 - 3 } & Números & Porcentajes \\
\hline Pulperos & 141 & $41 \%$ \\
\hline Comerciantes & 75 & $22 \%$ \\
\hline Dependientes & 65 & $19 \%$ \\
\hline Tenderos & 54 & $16 \%$ \\
\hline Almaceneros & 10 & $3 \%$ \\
\hline Total & $\mathbf{3 4 5}$ & $\mathbf{1 0 0} \%$ \\
\hline
\end{tabular}

Cuadro 2. Clasificación de las actividades comerciales de los gallegos en la ciudad de Buenos Aires, hacia $1810^{12}$

¿Quésignificado poseían estas actividades en el contexto colonial rioplatense? Simplificando un panorama bastante complejo podríamos señalar que, a grandes rasgos, los comerciantes se diferenciaban de los almaceneros, tenderos y pulperos en la medida en que estas tres últimas figuras se dedicaban a actividades minoristas, para el abastecimiento generalmente local, mientras que los primeros dominaban los intercambios de tipo mayorista, operando con un importante principal y monopolizando el uso de la moneda (Almanak Mercantil 1802: 399, Garavaglia 1970: 124, Socolow 1991: 25). No obstante ello, los comerciantes también podían realizar operaciones a pequeña escala, con lo cual, las barreras entre unos y otros son difíciles de trazar. Además, más allá de esta primera diferenciación, podríamos agregar que los tenderos se dedicaban a la venta de ropa y otros géneros (Millau 1947: 63), los almaceneros se concentraban en los ramos de loza, frutas, bebidas, caldos y suelas (García Belsunce 1976: 266-267) y los pulperos ponían a disposición del público una variada gama de productos (entre los que se destacaban los comestibles, las bebidas y las vestimentas), superponiéndose en muchos casos con la oferta de mercancías de las tiendas y almacenes (Blondel 1968: 181; Mayo, Miranda y Cabrejas 1996: 44). Dentro de cada uno de estos grupos mercantiles había una jerarquía interna que dependía en gran medida del tamaño del negocio, del beneficio bruto y ganancias que producía el mismo. Además, los

12 Fuentes: Archivo General de la Nación (Buenos Aires, Argentina), División Colonial, Sección Gobierno, Sala IX 9-7-7, Padrones generales de los habitantes de Buenos Aires de 1806 y 1807; Sala IX 10-7-1, Censo de Buenos Aires de 1810. 
mencionados grupos generalmente tenían empleados asalariados, a quienes se denominaba "dependientes", "mancebos" o "mozos" (la tercera categoría en el Cuadro 2). Estos últimos se encargaban de vender al público o de realizar, en algunos casos, operaciones mercantiles en diferentes puntos del espacio americano, según las indicaciones de sus contratadores (Socolow 1991: 130). En pocas palabras, dentro del conjunto de gallegos dedicado al intercambio mercantil se puede apreciar una importante heterogeneidad, en cuanto a la escala de las operaciones en las que se involucraban sus miembros o en relación con la magnitud de los capitales acumulados en la colonia. Encontramos desde comerciantes de cierta importancia, hasta pulperos con un limitado giro, pasando por una variada gama de situaciones intermedias.

Ahora bien, si analizamos globalmente el tipo de actividades comerciales desplegadas por los gallegos (Cuadro 2), podremos deducir el gran peso que tuvieron entre las mismas las de tipo minorista, tomadas conjuntamente (los pulperos, tenderos y almaceneros constituyeron el $60 \%$ del grupo dedicado al comercio). Según los estudios de Bentancur (1999: 107-108), en la vecina ciudad de Montevideo, a fines del siglo XVIII, los peninsulares del noroeste hispánico también alcanzaron un dominio importante de los circuitos minoristas. Esta inclinación no impidió que en muchos casos, a ambas orillas del Río de la Plata, los inmigrantes en cuestión transitaran caminos de movilidad social ascendente, muchas veces, ampliando sus operaciones dentro del mismo ámbito mercantil (sobre ello volveremos en el próximo apartado).

Remitiéndonos al universo de actividades comerciales minoristas destaca el lugar ocupado por los gallegos pulperos. Estos últimos llegaron a representar algo más de la mitad $(56 \%)$ del conjunto de españoles que se desempeñaban como pulperos (García Belsunce 1976: 266-267). Por lo tanto, podemos concluir que los gallegos pulperos tuvieron un peso importante no sólo entre los migrantes de dicha procedencia, sino también en relación con la población española-europea en general, instalada en la capital virreinal.
La inserción como pulperos implicó para muchos inmigrantes del noroeste hispánico convertirse en objeto de desdén y prejuicios negativos, tanto por parte de sus coterráneos de la elite local, como por parte de los criollos, mestizos, negros, mulatos o indios que constituían su clientela. Como ha afirmado Mayo (1996: 130): "El pulpero peninsular era, en efecto, el otro español, el español oscuro, pobre, desprestigiado socialmente, que se mezclaba con la plebe, que trataba cara a cara con la población criolla de la ciudad, el español olvidado por la Historia colonial".

El descrédito hacia los pulperos y el estigma asociado a los mismos no sólo eran alimentados por quienes los rodeaban, sino que también eran asumidos por los mismos peninsulares dedicados a la actividad. Así lo puso de manifiesto el gallego José Monso, al momento de ordenar su testamento. Este español, arribado al Río de la Plata a fines del siglo XVIII, había logrado entrar en sociedad con su compadre Antonio Fecha, para la administración de una casa de abasto (pulpería). Al dejar establecida su última voluntad, en lo relativo al destino de sus bienes materiales, estipuló que "para descargo de mi conciencia por lo que pueda haber ofendido al público en el ejercicio de la pulpería que he tenido, se dé de limosna ochenta pesos, sacados estos de todo el fondo (...)"13. Las autoridades coloniales, convencidas de que en las mencionadas casas de abasto se desarrollaba el "vicio popular", las concibieron como un ámbito potencialmente peligroso. Al calor de la guitarra, los juegos de naipes y el alcohol que en ellas circulaba, solían juntarse varios parroquianos, muchas veces llegados de los arrabales de la ciudad. Estas "juntas de indecentes y mal entretenidos" pronto se convirtieron en el blanco de los ataques de los funcionarios españoles, quienes las consideraron amenazadoras del orden social (Wilde 1917: 268-269).

\section{Las formas de ingreso al ejercicio comer- cial}

La inclinación por el desempeño de actividades comerciales se vio estimulada por la existencia de variadas vías de ingreso a las mismas, algunas de las cuales resultaban accesibles incluso 
para quienes llegaban con escasos o nulos capitales al Río de la Plata.

En primer lugar, el inmigrante peninsular podía recibir en préstamo una suma de dinero, con la cual podía comenzar su negocio. La cantidad requerida para ello no era elevada, según algunos testimonios de la época: con menos de 500 pesos de principal se podían adquirir algunos bienes (por ejemplo, un barril de vino, frascos de aguardiente, velas, géneros, entre otros) que se colocaban a la venta, en los huecos que dejaba la irregular arquitectura de la ciudad porteña ${ }^{14}$. El dinero inicial para comenzar este tipo de negocio era aportado generalmente por paisanos ya instalados en Buenos Aires (Furlong 1953: 90-91) o por la esposa (o la familia de ésta), en la forma de una herencia paterna o una dote introducidas a la sociedad conyugal al momento del matrimonio, por ejemplo ${ }^{15}$. En esta dirección, un casamiento "conveniente" podía facilitar el ingreso al mundo comercial. Los inmigrantes gallegos presentaron una fuerte tendencia a la exogamia matrimonial, puesta de manifiesto en los numerosos enlaces contraídos con consortes criollas de la colonia (De Cristóforis 2008: 202-203) ${ }^{16}$. Este comportamiento, condicionado por el limitado número de mujeres gallegas instaladas en la capital virreinal, no sólo permitió la integración de los recién llegados en la sociedad colonial, sino que también actuó como un efectivo mecanismo de ascenso social.

Cuando el inmigrante no tenía acceso a una mínima cantidad de dinero para montar un pequeño negocio, podía conchabarse como dependiente o mozo. En calidad de tal no recibía un salario mensual, sino que sus haberes eran retenidos por su empleador y eran abonados de manera conjunta, cuando terminaba de prestar sus servicios o cuando su patrón fallecía. Al momento de efectivizarse el pago, el empleador descontaba del monto total a abonar los gastos personales de su mozo (la ropa de uso o incluso, dinero en efectivo), por lo cual este último podía llegar a percibir una ganancia mínima ${ }^{17}$.

El desempeño como dependiente, si bien conllevaba restricciones a la movilidad y la obligación de acatar las decisiones del patrón, muchas veces arbitrarias, también podía implicar ciertos beneficios para el inmigrante. En primer término, el empleador le brindaba alimento y alojamiento, lo que suponía una gran ventaja para aquellos recién llegados que no tenían en principio dónde vivir. En segundo término, muchas veces los patrones recompensaban a sus mozos por los buenos servicios prestados, ya sea con una fracción de su herencia (más frecuente en los casos de los patrones solteros) o incluso, con una habilitación. Esta última implicaba la conformación de una sociedad comercial, en virtud de la cual se establecían derechos y obligaciones recíprocos entre las partes, por cierto tiempo y bajo condiciones estipuladas de antemano (Mariluz Urquijo 1971, 92-121).

El ingreso a una compañía suponía que el dependiente había dado muestras suficientes de idoneidad y fidelidad, lo que conducía a que fuera "premiado", al ser ascendido al status de "socio" de su empleador ${ }^{18}$. En esta nueva situación, el último lo podía integrar a su negocio, en calidad de "administrador". Las utilidades eran divididas entre ambos, a pesar de que muchas veces, los antiguos mozos aportaban tan sólo su "industria y trabajo" a la nueva sociedad. Esto es lo que le ocurrió al gallego Antonio de Castro y Romero. En reconocimiento a su buen desempeño como dependiente, a lo largo de diez años de servicios, Domingo López lo terminó asociando a su pulpería. El último introdujo unos "seis mil y más pesos" en principal, mientras que Castro y Romero aportó "su industria", es decir, su trabajo personal ${ }^{19}$. El gallego Mateo Suárez

14 AGN, DC, Comerciales, S IX 31-1-6, Leg. n 20, Exp. 5, f. 6.

15 Cf., entre otros casos: AGN, Protocolos Notariales, Reg. n 6, 1804, ff. 325-324; AGN, Sucesiones 6777, Testamento de Ildefonso Faramiñán, f. 17.

16 A partir del análisis de las actas matrimoniales de las parroquias de la ciudad de Buenos Aires se ha comprobado que un $98 \%$ de los casamientos llevados a cabo por los inmigrantes gallegos en la capital virreinal, entre $1770 \mathrm{y}$ 1812, fueron con mujeres criollas, mayoritariamente porteñas (De Cristóforis 2008: 202-203).

17 AGN, Sucesiones 4840, Testamento de José Carraselas, ff. 2, 17.

18 AGN, Sucesiones 8141, Manuel Ayres contra la testamentaria de Juan de Silva Cordeyro por cobro de pesos, 1808, f. 10 .

19 AGN, Protocolos Notariales, Reg. no 3, 1804, f. 144. 
también se vio beneficiado cuando su patrón, Alejandro Invaldi, lo habilitó en una pulpería diferente a la que trabajaba inicialmente, a partir de utilidades. Las nuevas responsabilidades adquiridas lo obligaron a delegar el cuidado del primer negocio en manos del mozo Juan, al tiempo que era asistido en las tareas domésticas por tres $\operatorname{criados}^{20}$. En otras circunstancias, el socio principal podía adelantar una cierta cantidad de dinero en efectivo o en efectos a su habilitado, para la realización de un determinado giro, a partir de utilidades.

Cabe aclarar que en algunos casos, los inmigrantes podían ser habilitados sin haber pasado previamente por la condición de "mozos" del socio principal. Incluso, algunos dependientes lograron habilitar a otros sujetos, empleando el dinero de sus patrones como si fuera parte de sus gastos personales ${ }^{21}$. Transformarse de "habilitado" en "habilitador" podía constituir una etapa más dentro del proceso de movilidad social descripto. Tal fue el caso de José Durán y Antonio Ortiz, que tras haber sido habilitados en el almacén del gallego José Seoane, pasaron a ser socios de éste, en la pulpería que quedó constituía el 1 de abril de 1815, convirtiéndose más tarde en habilitadores, junto con Seoane, de los gallegos José Villar y Francisco Patiño. Según la contrata suscrita, estos últimos quedaron sujetos a la atención del mostrador de la mencionada casa de abasto ${ }^{22}$.

El hecho de que las utilidades tendieran a dividirse en partes iguales implicaba una gran ventaja para el socio inmigrante, que muchas veces aportaba tan sólo su "industria y trabajo" a la sociedad, como quedó de manifiesto en un ejemplo anteriormente comentado. Si el negocio marchaba bien, al final del ejercicio comercial el peninsular del noroeste hispánico podía contar con un cierto capital, que lo habilitaba para iniciar su propio giro, de manera más independiente. Veamos un caso concreto. Cuando en mayo de 1805 Ramón de Otaola estableció el contrato de compañía con José Carraselas, oriundo de Pontevedra, por el manejo de una tienda, el primero introdujo a dicha sociedad 4000 pesos, mientras que el segundo, su trabajo como administrador ${ }^{23}$. Hacia 1812, luego del fallecimiento de Carraselas, se llevó a cabo la liquidación y partición de cuentas de la mencionada compañía, que arrojó como resultado un caudal partible entre ambos de 4720 pesos. Los gananciales para cada uno de los socios fueron de 2360 pesos $^{24}$.

En otros casos el inmigrante estaba en condiciones de incorporar su propio capital a la sociedad. Así lo hizo el gallego Domingo Antonio de Pasos, quien fue habilitado por su sobrino, en una pulpería ubicada en la Plaza Mayor (en un cuarto de Antonio José Escalada). El primero colocó en el fondo unos 798 pesos, mientras que el segundo, 763 pesos. Según el balance y tasación de los efectos y utensilios de la casa de abasto en cuestión, efectuado en 1811, a Domingo de Pasos le correspondieron unos 1839 pesos. Vemos entonces cómo este inmigrante, a lo largo de su ejercicio comercial como habilitado, también obtuvo ganancias para nada desdeñables ${ }^{25}$.

Debemos aclarar que, más allá de estas posibilidades de "éxito económico", también existieron los balances desfavorables. Incluso, podía ocurrir que la habilitación no se llegara a concretar, permaneciendo como una promesa indefinida, que a lo sumo garantizaba el esfuerzo laboral de los mozos que esperaban beneficiarse de la misma. Muchos de los jóvenes que anhelaban ser habilitados, al comprobar

20 AGN, Sucesiones 8141, Testamento de Mateo Suárez, ff. 3, 17-18.

21 AGN, Sucesiones 8151, Don Domingo Viera solicitando ajuste de cuentas a los Albaceas de la Testamentaria de Don Carlos Santa María, ff. 5, 6 y 25.

22 AGN, Sucesiones 8145, Testamento de José Seoane, f. 3; AGN, Sucesiones 8605, Testamento de José Villar; AGN, DC, Sección Gobierno, S IX 10-7-1, Censo de Buenos Aires de 1810.

23 AGN, Sucesiones 4840, Testamento de José Carraselas, f. 5.

24 AGN, Sucesiones 4840, Testamento de José Carraselas, ff. 27-28. Aclararemos que para conocer con exactitud el haber que finalmente le correspondió al gallego, habría que descontar los gastos personales efectuados por el mismo a lo largo del tiempo que duró la sociedad, cuestión que lamentablemente no quedó consignada en la sucesión testamentaria analizada.

25 AGN, Sucesiones 7385, Testamento de Domingo Antonio de Pasos, ff. 6-8; AGN, DC, Sección Gobierno, S IX 10 7-1, Censo de Buenos Aires de 1810. 
que sus patrones no tenían intenciones de hacerlos partícipes de una empresa comercial en calidad de socios, retornaban a la península, desencantados por el fracaso de su cometido ${ }^{26}$.

Con sus efectos positivos o negativos, la habilitación alcanzó una importante difusión dentro de la sociedad porteña de fines del siglo XVIII y comienzos del XIX. Su modalidad de funcionamiento se adaptó muy bien a las condiciones del comercio colonial rioplatense. Tengamos presente que este último se caracterizaba por la multiplicación de negocios a pequeña escala, a tal punto que la expansión de una empresa no se exteriorizaba por el aumento de la magnitud de su capital, sino por la proliferación de nuevos locales, que quedaban a cargo de diferentes administradores (Mariluz Urquijo 1971: 117-118). Esta estrategia permitía reducir los riesgos que se derivaban del elevado carácter especulativo de las transacciones comerciales, en la medida en que las eventuales pérdidas producidas en un negocio, podían ser compensadas con las ganancias logradas en otro. Detengámonos brevemente en el análisis de algunas situaciones donde se puede apreciar cómo se podían ampliar las operaciones, a partir de la participación en una empresa.

En el año 1814, el gallego José Galloso puso una tienda con su socio Antonio Rodríguez Peña. El primero proporcionó 4000 pesos en efectivo, mientras que el segundo, 600 pesos Transcurrido un cierto tiempo, los socios sacaron del principal unos 4000 pesos, con los que instalaron otra tienda. Al frente de la misma colocaron a Juan Antonio Garzón, a partir de utilidades entre los tres. En el año 1820, Rodríguez Peña pasó a la Banda Oriental, quedando en el primer negocio, como dependiente y a sueldo, Ramón Zorraguín. Luego, este último se incorporó a la compañía inicial que habían formado Galloso y Rodríguez Peña. Una vez transcurrido cierto tiempo, los tres socios decidieron sacar del principal de la tienda unos
700 pesos, que invirtieron en la pulpería de un hombre llamado Tomás, acordando que en la misma los tres primeros se dividirían por partes iguales la mitad de gananciales y el último se quedaría con el resto. Hasta este momento, Galloso había participado en tres empresas: dos tiendas y una pulpería (además de algunas otras iniciativas previas, que suponemos debe haber tenido). También poseía una fábrica de sombreros ordinarios, con un principal "como de mil y más pesos", a cargo del dependiente Vicente Cádiz ${ }^{27}$. Vemos entonces cómo este inmigrante diversificó sus inversiones, multiplicando sus negocios. Las utilidades que rindieron los primeros no se dirigieron a ampliarlos, sino que fueron empleadas para iniciar o ingresar en nuevas empresas (como en el caso de la segunda tienda y más tarde, de la pulpería).

También el gallego José Monso utilizó parte del capital obtenido en la sociedad que mantuvo con Antonio Fecha, por el manejo de una casa de abasto (en la que había sido habilitado, a partir de utilidades), en una nueva empresa: una pulpería en las inmediaciones de San Isidro, en la que puso el principal y habilitó a Alonso Fernández ${ }^{28}$. Finalmente, Agustín Zabané, oriundo del Obispado de Tuy, llegó a tener inversiones en tres pulperías: en las dos primeras, había puesto la mitad del principal y esperaba obtener el $50 \%$ de las ganancias, en sociedad con Juan Manuel Rodríguez. En la tercera, en cambio, había aportado todo el principal e incluso, había designado un administrador, Andrés Llamas, quien debía girarla, a partir de utilidades ${ }^{29}$.

Por las perspectivas de movilidad social ascendente que abría, la habilitación llegó a generar amplias expectativas entre los jóvenes españoles que arribaban a la capital virreinal y entre aquellos otros que aún permanecían en suelo metropolitano. Incluso, la posibilidad de promoción en el ámbito mercantil ejerció un fuerte poder de atracción sobre los emigrantes de origen peninsular en otros espacios

26 AGN, Sucesiones 8141, Manuel Ayres contra la testamentaria de Juan de Silva Cordeyro por cobro de pesos, 1808, f. 2; AGN, Sucesiones 8151, Don Francisco Pico y Gradilla cobrando a la Testamentaria de Don Carlos Santa María cantidad de pesos, f. 55; AGN, FBN, Patagonia. Documentos del Archivo de Indias, Leg. n 196, "Breve descripción de las circunstancias en que se halla la Provincia de Buenos Aires", 1778, ff. 7-8.

27 AGN, Sucesiones 5912, Testamento de José Galloso, ff. 3-4.

28 AGN, Sucesiones 6779, Testamento de José Monso, ff. 2, 42.

29 AGN, Sucesiones 8144, Testamento de Agustín Zabané, ff. 2, 3, 7-12, 13-25. 
americanos, alejados del rioplatense. Así lo ha comprobado Yáñez Gallardo (1996: 209), en relación con los catalanes que se dirigieron a las Antillas, por ejemplo.

\section{Conclusiones}

El comercio constituyó un importante ámbito de inserción laboral para los inmigrantes gallegos en el Buenos Aires tardo-colonial. Estos peninsulares lograron una destacada presencia en los circuitos minoristas, como pulperos o tenderos, abasteciendo de productos necesarios a la población local e interactuando con ella directa y constantemente. Las características del comercio porteño, que en ese entonces ofrecía vías de ingreso bastante abiertas a los recién llegados, o la presencia y efectivo accionar de redes étnicas y familiares, contribuyeron a que las actividades mercantiles se instituyeran en un importante "nicho laboral" de los oriundos del noroeste hispánico, dentro de la capital virreinal. Por supuesto que no fueron los únicos españoles que aprovecharon las oportunidades brindadas por los intercambios comerciales, pero en virtud de su destacada participación en los circuitos minoristas alcanzaron una especial "visibilidad", de cara a quienes eran sus compradores. Posteriormente, y en el contexto del desencadenamiento del proceso revolucionario, esa visibilidad los convirtió en muchos casos en un blanco predilecto del odio de la plebe, que no dudó en concebirlos como enemigos del gobierno patrio surgido en 1810 (Mayo 1996: 130). Además, la nueva elite dirigente nacida de la ruptura del pacto colonial implementó una amplia normativa anti-peninsular, que incluyó la prohibición para los españoles europeos de administrar casas de abasto (Galmarini 1986: 561-592, Registro Oficial 1879: 172), medida que afectó negativamente a los pulperos, entre ellos, a los de origen gallego a los que hemos aludido en nuestro trabajo.

Los mecanismos de acceso al mundo comercial comentados precedentemente (obtención de capitales a través de paisanos o de la esposa, desempeño como mozo asalariado, habilitación) no fueron los únicos que facilitaron el ingreso a los circuitos de intercambios, ni tampoco operaron en todos los casos de manera separada. Como ha quedado sugerido, muchas veces actuaron de forma sucesiva, o incluso, paralela. Dichos mecanismos supusieron la movilización de recursos relacionales, es decir, se basaron o activaron el tejido social que podía poseer o generar el inmigrante. La incorporación a una tienda en calidad de mozo, o a una compañía como socio, no dependía únicamente de las capacidades que el joven peninsular pudiera poseer y demostrar, sino también del tipo de red en la que estuviera inserto, de la eficacia de sus lazos. Algunas veces, como pusimos de manifiesto, eran los vínculos étnicos los que garantizaban el ingreso al ámbito mercantil, pero también tenemos alguna evidencia de cómo los familiares (entre tíos-sobrinos, hermanos o concuñados, además del caso de los esposos, ya citado) podían cumplir la misma función, con variable éxito ${ }^{30}$.

El papel de las relaciones sociales en el acceso de los inmigrantes gallegos a los circuitos comerciales de la capital virreinal también puede pensarse en el largo plazo. El desempeño de actividades mercantiles probablemente estuvo condicionado por la más temprana y favorable inserción en ellas de algunos gallegos, que luego permitieron o facilitaron la acomodación de sus paisanos, arribados con posterioridad. Si dirigimos nuestra atención al padrón de habitantes de Buenos Aires de 1744, que presenta en un buen número de casos la procedencia regional de los peninsulares, comprobaremos que hacia mediados del siglo XVIII el pequeño grupo de gallegos asentados en la mencionada ciudad se dedicaba de manera preponderante a las actividades comerciales, en especial, a aquellas vinculadas con tiendas y pulperías ${ }^{31}$. Si bien las cifras son muy exiguas, permiten suponer que desde antes que los flujos desde Galicia hacia la América austral se incrementaran, existía una modesta comunidad de dichos orígenes que sobrevivía gracias a los intercambios mercantiles. Es posible que dicha comunidad haya

30 AGN, Sucesiones 7385, Testamento de Domingo Antonio de Pasos; AGN, Sucesiones 6498, Testamento de Antonio de Lema; AGN, Sucesiones 5345, Testamento de Miguel de Caldevilla, entre otros.

31 De los 31 gallegos cuya ocupación quedó consignada en el citado padrón, 24 (77\%) se dedicaban a actividades comerciales (Facultad de Filosofía y Letras 1920a: 328-506). 
transmitido parte de su experiencia a ulteriores inmigrantes (por ejemplo, valiosa información acerca de cómo ingresar y operar dentro de los circuitos de intercambios coloniales rioplatenses) o haya actuado como promotora de la llegada de otros gallegos que también se ubicaron en el comercio. Futuros trabajos podrán corroborar el funcionamiento de estos eslabonamientos tempranos, en el contexto de una sociedad en constante crecimiento y transformación.

De igual modo, consideramos que la estructura laboral de los gallegos de comienzos del siglo XIX influyó sobre el proceso de inserción ocupacional de los inmigrantes del noroeste hispánico que arribaron posteriormente, a partir de mediados de dicha centuria. Como sugerimos anteriormente, con el transcurso del tiempo la proporción de gallegos ocupados en actividades dependientes y/o poco calificadas (peones, jornaleros, empleados/as domésticos/ as, entre otras) aumentó, en parte debido a que las corrientes inmigratorias se tornaron más masivas y menos selectivas. No obstante ello, las tareas comerciales conservaron un peso importante dentro de la estructura laboral de la comunidad gallega -así como dentro de la española en general (Moya 2004: 220-221)-, ubicándose en segundo lugar, luego de las primeras. Si bien sería necesario profundizar nuestra presunción con investigaciones venideras, creemos que el último fenómeno mencionado se vinculó en buena medida a la existencia y accionar de redes microsociales generadas entre paisanos o familiares, que cifraban sus orígenes en la etapa tardo-colonial y que auspiciaron la llegada de congéneres que podían asumir la continuidad de los negocios comerciales. Dichas redes lograron perpetuarse a través de varias décadas, a pesar de que algunas coyunturas políticas, como la ruptura del pacto colonial y la hispanofobia desencadenada a raíz de las guerras revolucionarias, las obligaron a mantenerse poco activas o inactivas durante algunos años (De Cristóforis 2010: 144-145). En efecto, a partir de la Revolución de Mayo (1810) no hubo condiciones propicias para el arribo de peninsulares al Río de la Plata, pero cuando las corrientes inmigratorias desde España se reactivaron, en las décadas centrales del siglo XIX, lo hicieron sobre la base de las precedentes, a través de la revitalización de antiguas cadenas migratorias. De allí que la inserción de los gallegos en el pequeño comercio minorista urbano, a principios del siglo XX, no pueda ser comprendida cabalmente sin tener en cuenta los antecedentes generados por las migraciones gallegas de la etapa tardo-colonial.

\section{Referencias Bibliográficas}

Akerman, Sune; Hans Christian Johansen y Robert Ostergren (1990): Long-Distance Migration in Scandinavia 1500-1900. XVIIe Congrès International des Sciences Historiques (Madrid 1990). Madrid: Umeå.

Almanak Mercantil ó Guía de Comerciantes para el año de 1802 (sic) (1802). Madrid: Vega y Compañía.

Bentancur, Arturo Ariel (1999): "12 semblanzas de gallegos en el Montevideo colonial”, Anuario del Centro de Estudios Gallegos, pp. 103-113.

Blondel, Juan José (1968): Almanaque político y de comercio para 1826. Buenos Aires: Ediciones de La Flor.

Botelho, Tarcísio R. y Marco H. D. van Leeuwen (orgs.) (2012): História Social: perspectivas metodológicas. Belo Horizonte: Veredas \& Cenários.

Cagiao Vila, Pilar y Xosé Manoel Núñez Seixas (2007): Os galegos de Ultramar. II. Galicia e o Río da Prata. A Coruña: Arrecife Eds. Galegas.

Cagiao Vila, Pilar y María Luisa J. Pazos Pazos (2007): Galicia e o mundo colonial americano. II. Os galegos en América (1700-1850). A Coruña: Arrecife Eds. Galegas.

Da Orden, María Liliana (2001): "La inmigración gallega en Mar del Plata: trabajo, movilidad y relaciones personales (1895-1930)”, en X. M. Núñez Seixas (ed.), La Galicia Austral. La inmigración gallega en la Argentina. Buenos Aires: Biblos (Col. La Argentina Plural), pp. 87-106.

De Cristóforis, Nadia Andrea (2008): "Migracións temperás e pautas matrimoniais: galegos e asturianos no Bos Aires tardocolonial”, Estudos Migratorios. Revista Galega de Análise das Migracións 1/1, pp. 195-214.

(2010): Bajo la Cruz del Sur: gallegos y asturianos en Buenos Aires (1820-1870). A Coruña: Fundación Pedro Barrié de la Maza (Col. Galicia Exterior). 
Delgado Ribas, Josep María (1982): "La emigración española a América Latina durante la época del comercio libre (1765-1820). El ejemplo catalán”, Boletín Americanista XXIV/32, pp. 115-137.

Devoto, Fernando (1992): Movimientos migratorios: historiografía y problemas. Buenos Aires: Centro Editor de América Latina.

Eiras Roel, Antonio (1991): "La emigración gallega a América. Panorama General”, en La emigración española a Ultramar, 1492-1914. Madrid: Ediciones Tabapress, pp. 17-39.

Eiras Roel, Antonio y Ofelia Rey Castelao (1992): Los gallegos y América. Madrid: Mapfre (Col. Las Españas y América).

Facultad de Filosofía y Letras (1920a): Documentos para la Historia Argentina. X. Padrones de la ciudady campaña de Buenos Aires (1726-1810). Buenos Aires: Peuser / Universidad de Buenos Aires.

- (1920b): Documentos para la Historia Argentina. XII. Territorio y Población. Buenos Aires: Universidad de Buenos Aires.

Farías Iglesias, Ruy Gonzalo (2010): La inmigración gallega en el Sur del Gran Buenos Aires, 1869-1960. Tesis doctoral. Santiago de Compostela: Universidade de Santiago de Compostela (http://www.europeana.eu/portal/record/2022701/oai_dspace_usc_es_10347_2784.html).

Figueira, Ricardo (2000): "Del barro al ladrillo", en J. L. Romero y L. Alberto Romero (dirs.), Buenos Aires. Historia de cuatro siglos. 1. Desde la Conquista hasta la Ciudad Patricia. Buenos Aires: Grupo Editor Altamira, pp. 107-125.

Furlong, Guillermo (1953): Pedro Juan Andreu y su carta a Mateo Andreu (1750). Buenos Aires: Librería del Plata.

Galmarini, Hugo Raúl (1986): “Los españoles de Buenos Aires después de la revolución de mayo: la suerte de una minoría desposeída del poder", Revista de Indias XLVI/178, pp. 561-592.

Garavaglia, Juan Carlos (1970): “Comercio colonial: expansión y crisis”, Polémica. Primera Historia Argentina Integral 5, pp. 122-140.

Garay Unibaso, Francisco (1978): Correos Maritimos Españoles a la América Española (Yndias Occidentales). Vol. I. De 1514 a 1827. Bilbao: Ediciones Mensajero.

García Belsunce, César A. (dir.) (1976): Buenos Aires. Su gente. 1800-1830. Buenos Aires: Emecé.

Gribaudi Maurizio y Alain Blum (1990): "Des catégories aux liens individuels: l'analyse statistique de l'espace social”, Annales E.S.C. 6, pp. 1365-1402.

Halperín Donghi, Tulio (1968): "Revolutionary militarization in Buenos Aires 1806-1815", Past and Present. A Journal of historical studies 40, pp. 84-107.

Johnson, Lyman L. (1979): "Estimaciones de la población de Buenos Aires en 1744, 1778 y 1810”, Desarrollo Económico 19/73, pp. 107-119.

Johnson, Lyman L. y Susan Midgen Socolow (1980): "Población y espacio en el Buenos Aires del siglo XVIII", Desarrollo Económico 20/79, pp. 329-349.

Lelo Bellotto, Manoel (1971): Correio Marítimo Hispano-Americano. A Carreira de Buenos Aires (17671779). Assis: Faculdade de Filosofía, Ciencias e Letras.

Mariluz Urquijo, José M. (1971): "Notas sobre la evolución de las sociedades comerciales en el Río de la Plata", Revista del Instituto de Historia del Derecho Ricardo Levene 22, pp. 92-121.

Márquez Macías, Rosario (1989): "La emigración gallega a América en la época del comercio libre (17651824)", Revista da Comisión Galega do Quinto Centenario 4, pp. 37-56.

(1991): "La emigración española en el siglo XVIII a América", Rábida 10, pp. 68-79.

(1993): "La emigración española a América en la época del comercio libre (1765-1824): el caso andaluz", Revista Complutense de Historia de América 19, pp. 233-247.

(1995): La emigración española a América (1765-1824). Oviedo: Universidad de Oviedo.

Marquiegui, Dedier (1993): “La inmigración española en la Argentina: los gallegos de Luján, 1880-1920", Ciclos en la historia, la economía y la sociedad 3/4, pp. 133-154.

Mayo, Carlos (1996): "La pulpería como empresa. El capital invertido y su origen. Las sociedades comerciales de pulperos", en C. A. Mayo (dir.), Pulperos y Pulperías de Buenos Aires 1740-1830. Mar del Plata: Universidad Nacional de Mar del Plata, pp. 25-42.

Mayo, Carlos; Julieta Miranda y Laura Cabrejas (1996): “Anatomía de la pulpería porteña”, en C. A. Mayo (dir.), Pulperos y Pulperías de Buenos Aires 1740-1830. Mar del Plata, Universidad Nacional de Mar del Plata, pp. 43-75.

Millau, Francisco (1947): Descripción de la Provincia del Río de la Plata (1772). Buenos Aires: Espasa Calpe (Col. Austral). 
Moreno, José Luis (1965): "La estructura social y demográfica de la ciudad de Buenos Aires en el año 1778”, América Colonial. Población y Economía. Anuario del Instituto de Investigaciones Históricas 8, pp. 151-170.

Moya, José (2001): "Los gallegos en Buenos Aires durante el siglo XIX: inmigración, adaptación ocupacional e imaginario sexual", en X. M. Núñez Seixas (ed.), La Galicia Austral. La inmigración gallega en la Argentina. Buenos Aires: Biblos (Col. La Argentina Plural), pp. 69-85.

(2004): Primos y extranjeros. La inmigración española en Buenos Aires, 1850-1930. Buenos Aires: Emecé.

Núñez Seixas, Xosé Manoel (2000): "Redes sociales y asociacionismo: las «parroquias» gallegas de Buenos Aires (1904-1936)", Estudios Interdisciplinarios de América Latina y el Caribe 11/1, pp. 23-44.

(2002): O inmigrante imaxinario. Estereotipos, representacións e identidades dos galegos na Argentina (1880-1940). Santiago de Compostela: Universidade de Santiago de Compostela.

(2007): "Un panorama social de la inmigración gallega en Buenos Aires, 1750-1930", en R. G. Farías (comp.), Buenos Aires Gallega. Inmigración, pasado y presente. Buenos Aires: Comisión para la Preservación del Patrimonio Histórico Cultural de la Ciudad de Buenos Aires.

(2014): Las patrias ausentes: Estudios sobre historia y memoria de las migraciones ibéricas (18301960). Oviedo: Genueve Ediciones.

Pérez, Mariana Alicia (2010): En busca de mejor fortuna. Los inmigrantes españoles en Buenos Aires desde el Virreinato a la Revolución de Mayo. Buenos Aires: Prometeo.

Registro Oficial de la República Argentina (1810-1873) (1879): 1. Registro Nacional (1810-1821). Buenos Aires.

Rey Castelao, Ofelia (2001): "Los gallegos en el Río de la Plata durante la época colonial”, en X. M. Núñez Seixas (ed.), La Galicia Austral. La inmigración gallega en la Argentina. Buenos Aires: Biblos (Col. La Argentina Plural), pp. 23-51.

Socolow, Susan Midgen (1991): Los mercaderes del Buenos Aires virreinal: familia y comercio. Buenos Aires: Ediciones de la Flor.

Villares, Ramón y Marcelino Fernández (1996): Historia da emigración galega a América. Santiago de Compostela: Xunta de Galicia.

Wilde, José Antonio (1917): Buenos Aires desde setenta años atrás. Buenos Aires.

Yáñez Gallardo, César (1996): Saltar con red. La temprana emigración catalana a América. Ca. 18301870. Madrid: Alianza.

Zubillaga Barrera, Carlos (1999): "Identidad étnica en la inmigración gallega en Montevideo hacia comienzos del siglo XIX”, en P. Cagiao Vila (ed.), Galicia nos contextos históricos (Semata 11). Santiago de Compostela: Universidade de Santiago de Compostela, pp. 175-190. 